\title{
Restorative Just Culture: a Study of the Practical and Economic Effects of Implementing Restorative Justice in an NHS Trust
}

\author{
Mannat Kaur ${ }^{1}$, Robert J. de Boer ${ }^{1,2, *}$, Amanda Oates ${ }^{3}$, Joe Rafferty ${ }^{3}$ \\ and Sidney Dekker ${ }^{1,4}$ \\ ${ }^{1}$ Art of Work Solutions Pty. Ltd., Brisbane, Australia \\ ${ }^{2}$ Northumbria University Amsterdam Campus, the Netherlands \\ ${ }^{3}$ Mersey Care NHS Foundation Trust, Liverpool, UK \\ ${ }^{4}$ Griffith University, Brisbane, Australia
}

\begin{abstract}
Restorative justice is an approach that aims to replace hurt by healing in the understanding that the perpetrators of pain are also victims of the incident themselves. In 2016, Mersey Care, an NHS community and mental health trust in the Liverpool region, implemented restorative justice (or what it termed a 'Just and Learning Culture') to fundamentally change its responses to incidents, patient harm, and complaints against staff. Although qualitative benefits from this implementation seemed obvious, it was also thought relevant to identify the economic effects of restorative justice. Through interviews with Mersey Care staff and collecting data pertaining to costs, suspensions, and absenteeism, an economic model of restorative justice was created. We found that the introduction of restorative justice has coincided with many qualitative improvements for staff, such as a reduction in suspensions and dismissals, increase in the reporting of adverse events, increase in the number of staff that feel encouraged to seek support and a slowing down of the upward trend in absence due to illness. It also improved staff retention. The economic benefits of restorative justice appear significant. After corrections for inflation, acquisitions and anomalies, we found that the salary costs averaged over two fiscal years were reduced by $£ 4$ million per year, coinciding with the introduction of a just and learning culture in 2016. In addition, Mersey Care reaped around $£ 1$ million in saved legal and termination expenses. We conservatively attribute half of these savings to the introduction of a just and learning culture itself, and the other half to non-related factors. Using this assumption, we estimate the total economic benefit of restorative justice in the case of Mersey Care NHS Foundation Trust to be about $£ 2.5$ million or approximately $1 \%$ of the total costs and $2 \%$ of the labour costs.
\end{abstract}

Keywords: Restorative Justice; Economic Benefits; Health Care.

\section{INTRODUCTION}

In this paper, we report on the practical and economic effects of implementing a restorative just culture in a medium sized NHS (National Health Service) trust in the north of England. Mersey Care is a community and mental health trust providing care for a population of over 11 million service users/patients in the North West of England and beyond. It is the largest provider of forensic learning disability services and is one of the major providers of high secure services in England. It employs about 8,000 staff members across more than 80 sites. In 2014, the disciplinary actions pertaining to employee-relations at Mersey Care was notably high, and during this time, the

\footnotetext{
* Corresponding author: +31(0)621156269, robert.deboer@northumbria.ac.uk

* Trust turnover at the time was $£ 260$ million; in April 2018 this has grown to $£ 360$ million.
} 
organization was focused on the disciplinary processes and intended to make them better and faster. To this end, the emphasis was also given to increasing HR training within the organization. However, by 2015, realizing that their current managerial and supervisory practices were not leading to desired improvements (like reduction in disciplinary actions or the time-taken), Mersey Care decided to fundamentally alter the way it responded to incidents (including suicides), patient harm, violence and complaints made against staff. Responses had previously been driven by human resource \& patient safety policies and practices that mostly (if unwittingly) followed a retributive just culture script-organized around rules, violations and consequences. This was replaced, over a period of 18 months, with restorative justice focused on understanding, healing and learning.

In a retributive just culture, the questions that are asked centre around culpability: it assesses how bad ("reprehensible") staff errors are; and accordingly administers proportional consequences (Marx, 2001; Reason, 1997; Wachter \& Pronovost, 2009). Such an arrangement has been shown to put downward pressure on people's willingness to come forward with bad news, and to change what people share and how they tell their stories when they do (Dekker \& Hugh, 2010; Dekker \& Laursen, 2007); it elides issues of substantive justice by ignoring broad staff support and the fairness of the rules applied (Dekker \& Breakey, 2016); it leaves the age-old procedural question of 'who draws the line' fundamentally unresolved (Dekker, 2009); and is linked less to justice than to organizational power: one's position in the medical competence and managerial hierarchies co-determines whether retributive responses are seen as 'just' (Dekker \& Nyce, 2013; von Thaden, Hoppes, Yongjuan, Johnson, \& Schriver, 2006).

Restorative just culture, originating in a variety of ancient traditions, and with recent applications to justice in for example schools and juvenile offending (Barton, 2003; Mulligan, 2009; Weitekamp, 1999; Zehr \& Gohar, 2002), asks very different questions: who is hurt; what do they need; and whose obligation is it to meet those needs? The success of restorative responses hinges on getting the community involved in collaboratively resolving those questions and arriving at a solution that is respectful to all parties (Braithwaite, 1989), such as, patients, families, caregivers, organizational representatives, regulators and legal and union representatives. It considers accountability in a forward-looking (rather than punitive, backwards-looking) manner, asking who needs to do what now, given their role and the expectations that come with it (Sharpe, 2003, 2004). Practices that reflect confession and repentance (e.g., reporting, disclosure, apology) can precede forgiveness and re-engagement (Berlinger, 2005). In restorative justice, an account is not seen as something that needs to be settled or paid, but as something that is told, shared and learned from (Dekker, 2016). The goals of restorative justice include moral engagement of stakeholders, reintegration of the caregiver into the community of practice, emotional healing of those affected by the incident, and, ultimately, organizational learning and improvement.

\subsection{The Changes at Mersey Care}

Through detailed in-person interviews conducted on-site, researchers were able to find common themes pertaining to the culture at Mersey care prior to the implementation of restorative justice practices. Subsequently, the changes implemented 2015 onward were also identified along with the commonly perceived effects of these implementations. The interview method is elaborated in chapter 2.

Prior to the introduction of restorative justices at Mersey Care, staff reported a major fear of being blamed for adverse events. Staff were not always telling the truth, and half of the clinical staff acknowledged that they felt inhibited to speak out about adverse events. There was a sense among staff that the organization was solely target-oriented and lacked openness and compassion. Many incidents led to suspensions pending an investigation (sometimes leading to an employment tribunal). The primary aim of the investigation was perceived to be to find a root cause which was followed by a disciplinary investigation, suspension and dismissal or sanction. Suspension was intended as a none-prejudicial act and as a measure to reduce risk pending an 
investigation but was perceived by staff as punishment. Costs associated with suspensions were rising, as were legal costs, agency costs for backfill absenteeism and staff turnover.

Over a period of 18 months, Mersey Care developed and implemented the following changes:

- From investigations of supposed offenders to restorative conversations between all stakeholders in the incident. This also involved a focus on myth/rumour busting by making factual information available sooner to other staff, where previously it was common not to share information during the investigation period.

- Freeze of staff suspensions unless contraindicated by evidence of threat.

- Culling judgmental language about staff performance from HR policies and procedures and patient safety post-incident reviews. Reviewing them (invitation to all staff for feedback) for clarity and necessity, and critically assessing them for the extent to which they actually empower and enable staff.

- Appointment (through self-nominations) of Just and Learning Culture lead to drive the organisational agenda, represent and advocate restorative justice and recruit ambassadors across the footprint.

- Appointment (through self-nominations) and training of just-culture ambassadors to represent and advocate for restorative justices across the trust's multiple sites.

- Revitalization of staff support through better advertising (like promotional banners, weekly CEO blogs), psychological first aid, debriefings and follow-up. This included 72-hour reviews (previously 5 working days), internal staff counselling services enabled to meet and connect with teams (also via telephone) following a serious incident.

- Sharing good practice stories (which are found by encouraging the staff to share their experiences) through a new internal 'just and learning culture' microsite-including not only clinical or operational successes but also lessons learnt, confessions made and gratitude extended.

- Encouraging the trickle-down of restorative just culture into everyday organizational life, including back-office and administrative work.

- Promoting just culture awareness through internal communication to affirm that things will be dealt with differently now.

These changes have been the subject of workshops at Mersey Care and also documented in various policy documents. This report is not intended to provide ways to achieve a cultural change. It, however, focuses on the effects of these interventions and highlights the various benefits.

\subsection{HR and other Policy Documents}

Mersey Care - like all large institutions - relies on written procedures and policies for much of its processes. These procedures generally serve five main purposes (Hale \& Borys, 2013):

- They are a memory aid for steps, especially in emergency situations

- To facilitate coordination between multiple actors

- As a basis for training

- As organisational memory, for example as the starting point for innovation - "how did we do that again?"

- To enable the monitoring and checking of behaviour (for example to prevent High Impact Low-Frequency events)

Procedures are static but need to provide guidance under the varying circumstances of dayto-day work. On the one hand, they need to offer sufficient guidance for practitioners, but on the 
other hand, the number of rule of exceptions ("non-compliances" or "violations") that they provoke needs to be minimised to retain credibility. We have looked at the following procedures:

- HR01 - Disciplinary Procedure

- HR07 - Management of attendance

- HR37 - Supporting Colleagues

- $\quad$ SA03 - Reporting, Management \& Review of Adverse Incidents

Whereas judgmental language (holding staff strictly accountable by procedure and compliance standards) was still present throughout Trust documentation, almost all procedures and policies now explicitly refer to or attempt to embody the values of a just and learning culture. Particularly the HR37 (Supporting Colleagues) policy is one that has been established as a result of the just and learning culture and this change in reflected in the simple language of the policy and a high emphasis on supporting staff. The organisation has refreshed all their organizational values to embody the Just and Learning language and has introduced a new value of 'Support' which specifically asks staff to raise concerns.

\section{METHOD}

The evaluation reported in this paper was conducted immediately after the implementation period of restorative justice (which had lasted 18 months). The researchers had no role in the operationalization of a 'just and learning culture' nor its practical implementation. They became involved-for the purpose of this paper-to assess its effects.

Over two separate periods of in total nine full days, researchers were present at trust headquarters as well as various sites. They were given unfettered access to accounting records, policies and procedures, as well as staff members themselves. Staff interviewed included Mersey Care's CEO, Executive Director of Workforce, Head of Health and Well-Being, Deputy Director of Workforce, Head of the Finance team, Business Intelligence team, Strategic Advisor Digital Programmes, Staff Side Chair, Deputy Medical Director, Strategic Organizational Effectiveness Lead and Head of Organizational Effectiveness and Learning. The aforementioned staff includes members who worked directly worked with the sharp-end of the organization before and during the implementation of restorative practices. Also included are those that recognized the retributive culture and those who instigated and drove this cultural change within the organization. During these interviews, the researchers focused on understanding the organization's journey through an (ongoing) cultural change and its perceived effects by the staff. The data analysis of staff absenteeism, disciplinary cases etc. was performed after correcting the data for known changes in the organization (such as acquisitions) to make the yearly numbers comparable. The costs analysed were based on annual accounts split per division and corrected for inflation and for acquisitions. The cost model was validated with Mersey Care staff before the savings calculations were made. The associated costs for making the changes have been included as part of the total operating costs of the organization and are therefore reflected in the economic analysis. The policies assessed for this study were HR01 Disciplinary Procedure; HR07 Management of Attendance; HR37 Supporting Colleagues; and SA03 Reporting, Management and Review of Adverse Events.

\section{RESULTS}

\subsection{Staff Experience}

During the interviews with Mersey Care staff, and following up with the analysis of the data such as disciplinary cases, incident reporting etc., we were able to identify numerous intangible benefits resulting from the implementation of the just and learning culture at Mersey Care. Below are examples of staff experience benefits that have been instigated or enabled by the 
organizational culture change:

- Increase in good faith and sensemaking

- Building trust within the different levels of the organization and also for the system

- Staff feel more enabled and are aware that the system should be in place to enable them to perform their best

- Awareness of a just and learning culture within the organization helps diffuse stressful situations and restore calm as staff knows things are changing

- An understanding that there is no compassion for patients without compassion for staff

- Increase in compassionate leadership

- Increase in psychological safety within teams

- Increase in understanding the relationship between teams' psychological safety and patient safety

- $\quad$ No knee-jerk reaction to unexpected events

- Prioritizing safety, physical and psychological, over all else (while "safety first" is a common notion in high-risk places, a culture that truly accommodates for it is a different goal)

- Reduction in psychological stress

- $\quad$ Staff feels more engaged, open and able to speak up

- Increased motivation

- Changing perspective around accountability and human error

- Tendency to find a local resolution

- Increased sense of personal learning among staff

- Increased staff engagement with senior leaders

- $\quad$ Recognizing 2nd victims and providing support

- Unblocking specific barriers that were affecting the staff's ability to work in-line with Mersey Care's leadership programs

- Making the process of special payments faster, thereby reducing psychological stress for the involved parties

- An open and accommodating work environment that facilitates honestly and learning

- Increase in morale and job satisfaction

While not all, many of the above benefits can be substantiated by (cost) data analysis to demonstrate the tangible and economic benefits generated by restorative practices. The next sections detail the same. In these descriptions we have endeavoured to report relative rather than absolute numbers to nullify scaling effects. Financial data has been corrected for acquisitions and inflation. In other cases, we assume that the volume of staff and activities during the represented time-period stay more-or-less the same.

\subsection{Tangible (non-economic) Effects of Restorative Practice}

All the data was corrected for known changes in the organization, like acquisition of several smaller institutions through the years. This was done to make the yearly data comparable against constant staff numbers to assess the effects of restorative interventions.

The implementation of restorative practice at Mersey Care has improved the quality of employment for many staff members. The just and learning culture has had a strong downward effect on the number of suspensions and disciplinary cases. In the period from April 2014 until March 2018, the disciplinary and suspension cases for the two operational units at Mersey Care was reduced from 66 before to 37 after the introduction of restorative practice. The just and learning culture has also led to an increase in reporting adverse events of between $7 \%$ and $18 \%$ per year from 2014 to 2017 . We assume that the actual number of incidents occurring during the 
represented time-period stays more-or-less the same so that the increase in reports signals a more open and trusting culture.

In a just and learning culture where trust, compassion and good faith have increased it is expected that employees feel more encouraged to seek help. An increase in staff coming in for support for face to face counselling has been determined after the introduction of restorative justice: from an average of 283 requests per year in 2014 and 2015 to an average of 378 per year for 2016 and 2017. Similarly, in the last two years after restorative practices were introduced, there is a reduction in issues presented regarding bullying, career, formal procedures, health, job situation, employment, trauma and violence/assaults.

Absence due to illness includes work-related and personal reasons for reporting absence. In a just and learning culture, we expect three effects that influence absenteeism:

- Less work-related pressure and more support from staff due to the trust and compassion, possibly leading to a reduction in stress-related absenteeism.

- Less reluctance to report sick for work when justified due to less work-related pressure and more trust leading to an increase in justified absenteeism.

- More support from the employer to reduce the duration of the absence, leading to a reduction in absenteeism.

The net effect is expected to be a reduction in absenteeism. Indeed, with the introduction of a just and learning culture, we see that there is a drop-in absence due to illness and the previously increasing trend decelerates. The total effect is initially $0.5 \%$ point and grows to $1 \%$ point in 2017 . This data has been corrected for acquisitions as well as seasonal trends exhibited by sickness reports which are mainly during the winter months. We have excluded maternity leave, (un)authorized absence and other types of absences unrelated to sickness.

It is expected that as a result of the roll-out of the just and learning culture, staff retention is improved, and turnover is reduced. The data on staff turnover is quite volatile but since early 2015 the reduction is visible, as shown in Figure 1.

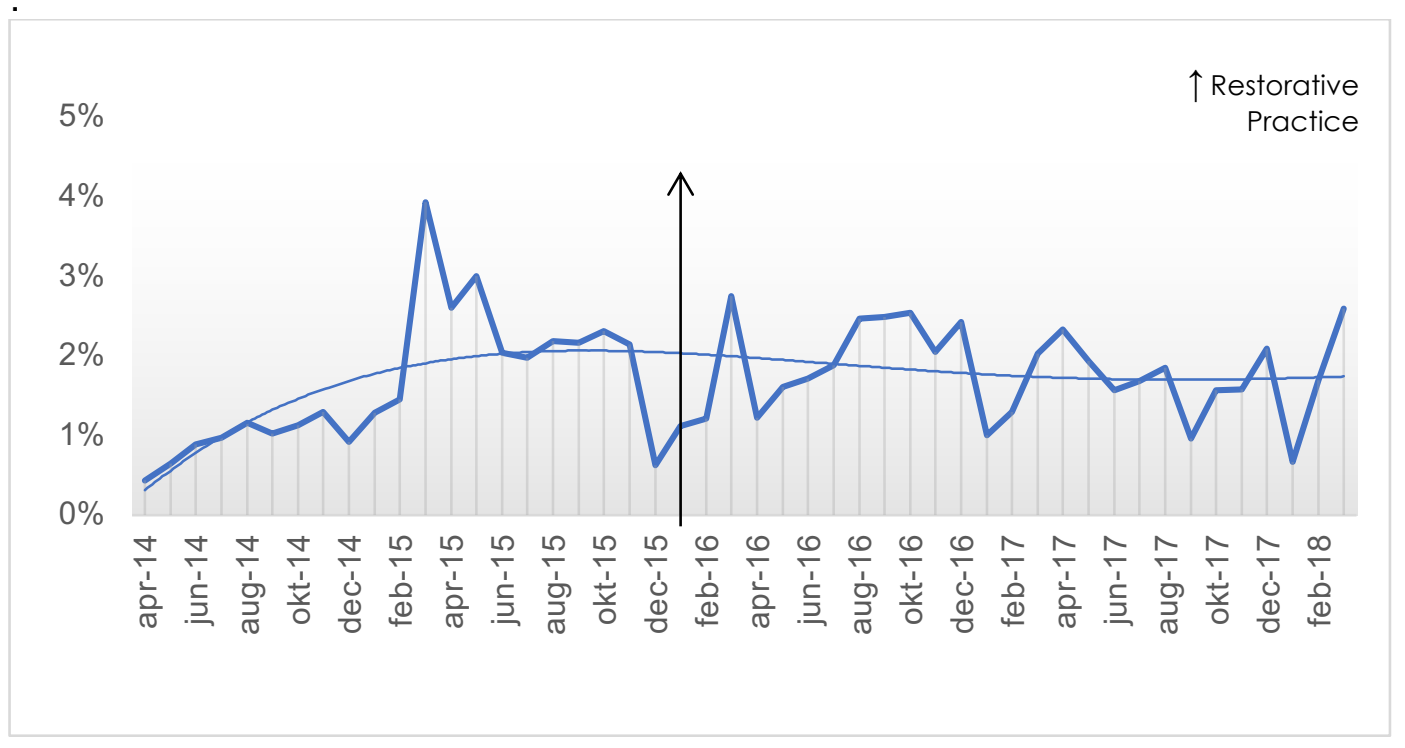

Figure 1: Total staff turnover rate

This data excludes all retirements and has not been corrected for acquisitions. Note that Mersey Care Trust is participating in the NHS Retention programme and has already been focused on improving staff retention. 


\subsection{Economic Effects}

As shown above, the implementation of restorative practices at Mersey Care has generated various benefits. The total cost base of Mersey Care in fiscal year 2017/2018 is approximately $£ 250$ million $^{\dagger}$. Of this around $70 \%$ are costs for salaries. To enable a fair comparison with preceding years the following corrections have been made:

- Acquisitions have been excluded that Mersey Care has acquired over the last few years.

- The costs have been corrected for inflation using the Consumer Price Index (CPI) in the United Kingdom.

Table 1 shows the corrected total costs and salary costs for the past four fiscal years at Mersey Care.

Table 1 Total costs and salary costs - raw data and corrected data

\begin{tabular}{|c|c|c|c|c|}
\hline & $2014 / 2015$ & $2015 / 2016$ & $2016 / 2017$ & $2017 / 2018$ \\
\hline TOTAL OPERATING COSTS & $£ 204$ mio & $£ 211$ mio & $£ 256$ mio & $£ 272$ mio \\
\hline TOTAL SALARY COSTS & $£ 150 \mathrm{mio}$ & $£ 151 \mathrm{mio}$ & $£ 163 \mathrm{mio}$ & $£ 198 \mathrm{mio}$ \\
\hline $\begin{array}{l}\text { \% SALARY COSTS OF } \\
\text { OPERATING COSTS }\end{array}$ & $74 \%$ & $72 \%$ & $64 \%$ & $73 \%$ \\
\hline $\begin{array}{l}\text { TOTAL OPERATING COSTS } \\
\text { (corrected for acquisitions) }\end{array}$ & $£ 204$ mio & $£ 211$ mio & $£ 228$ mio & $£ 216 \mathrm{mio}$ \\
\hline $\begin{array}{l}\text { TOTAL OPERATING COSTS } \\
\text { (corrected for acquisitions + inflation) }\end{array}$ & $£ 212$ mio & $£ 220$ mio & $£ 235$ mio & $£ 216$ mio \\
\hline $\begin{array}{l}\text { TOTAL SALARY COSTS (corrected } \\
\text { for acquisition) }\end{array}$ & $£ 150$ mio & $£ 151$ mio & $£ 139$ mio & $£ 154$ mio \\
\hline $\begin{array}{l}\text { TOTAL SALARY COSTS (corrected } \\
\text { for acquisition + inflation) }\end{array}$ & $£ 157$ mio & $£ 157$ mio & $£ 143$ mio & $£ 154$ mio \\
\hline $\begin{array}{l}\text { \% SALARY COSTS OF } \\
\text { OPERATING COSTS (corrected) }\end{array}$ & $74 \%$ & $72 \%$ & $61 \%$ & $72 \%$ \\
\hline $\begin{array}{l}\text { TOTAL OPERATING COSTS } \\
\text { (corrected \& } 16 / 17 \text { impairment costs } \\
\text { smoothed out) }\end{array}$ & $£ 212$ mio & $£ 220$ mio & $£ 218$ mio & $£ 216$ mio \\
\hline $\begin{array}{l}\text { \% SALARY COSTS OF } \\
\text { OPERATING COSTS (corrected \& } \\
16 / 17 \text { impairment costs smoothed } \\
\text { out) }\end{array}$ & $74 \%$ & $72 \%$ & $66 \%$ & $72 \%$ \\
\hline
\end{tabular}

A one-time cost for impairment was taken as part of operational costs in the fiscal year 2016/2017 and is unrelated to labour costs and restorative practice and has therefore been smoothed out in the bottom two rows of the table. The salary cost is the annual gross basic pay with no employer contributions or employee deductions. This figure does not include annual leave allowance and neither does it account for allowances paid in addition to basic pay, which will include shift allowances and 'lead' payments payable to staff who work in secure settings. This data also excludes other indirect labour costs such as staff education and training etc.

The average salary cost in fiscal years $14 / 15$ and $15 / 16$ ( $£ 157 \mathrm{mio}$ ) is higher than the average in fiscal years $16 / 17$ and $17 / 18$ ( $£ 148$ mio). This signifies a reduction of about $£ 9$ mio or $£ 4$ mio per year after correction of inflation, acquisitions and anomalies that coincides with the introduction of a just and learning culture in 2016. A general reduction may be expected due to productivity increases, and another part of this reduction is justified below for reduced illness leave and less 'suspension with pay'.

\footnotetext{
$\dagger$ In April 2018 this has grown to $£ 360$ million.
} 
As explained above, an improvement in absence due to illness of at least $0.5 \%$ point has coincided with the introduction of a just and learning culture to at Mersey Care after correcting for acquisitions and seasonal trends. This should equal an economic value of $0.5 \%$ of the total labour sum or $£ 500,000$. However, the sickness cost data shows a slightly more nuanced picture, perhaps because the absence due to sickness shifts from lower paid wage scales to higher bands. These expenses are $£ 87,000$ more in the year $2015 / 2016$ vs the previous year, whereas in the fiscal year $2017 / 2018$ vs $2016 / 2017$ we see total savings of $£ 19,000$. The difference according to this estimate amounts to about $£ 110,000$ rather than $£ 500,000$. The total trend for 'suspensions with pay' shows a clear reduction to coincide with the introduction of restorative practices as reported above, amounting to approximately $£ 50,000$ per annum.

Other savings that coincide with the introduction of a just and learning culture include legal costs and termination fees, which are additional to the savings in salary costs. There is a significant reduction in the number of disciplinary cases and suspensions coinciding with the introduction of a just and learning culture at Mersey Care, leading to a reduction in legal costs by $£$ 270,000 from $2016 / 17$ to $2017 / 18$, where previously legal costs were actually increasing. These include all expenditure on solicitors' fees across the organisation and corporate negligence costs. Similarly, termination costs have been significantly reduced by about $£ 700,000$ after the introduction of a just and learning culture, exclusive of Mutually Agreed Resignation Schemes costs.

In summary, after corrections for inflation and acquisitions, we have found that salary costs improved around 2016 when the just and learning culture was introduced. About $£ 4$ million per annum $(2.2 \%$. of total costs) savings were realized in staff costs, coinciding with the introduction of restorative practice. The savings are in part due to higher productivity, as well as reduced illness leave and less 'suspension with pay'. Additionally, savings of around $£ 1$ million in legal and termination costs have been identified to coincide with the introduction of the just and learning culture.

We conservatively attribute half of that savings to the introduction of a just and learning culture itself, and the other half to non-related factors. Using this assumption, we estimate the total economic benefit of restorative practice in the case of the Mersey Care NHS Foundation Trust to be about $£ 2.5$ million. This amounts to a meaningful saving as it is approximately $1 \%$ of the total costs and $2 \%$ of the labour costs. These estimates are based on a relatively short window after the introduction of restorative practice, and it remains to be seen whether these savings can be sustained.

\section{DISCUSSION AND CONCLUSION}

Implementation of restorative justice in Mersey Care has noticeable and apparently uniformly beneficial consequences for staff and organization alike, and also shows economic benefits. The intangible benefits include a downward effect (as expected) on the number of suspensions and disciplinary cases, an increase in staff coming in for support for face to face counselling, a reduction in absence due to illness, and improved staff retention. The economic effect is a meaningful saving of approximately $1 \%$ of the total costs and $2 \%$ of the labour costs. In the example of Mersey Care we see that after the move from a retributive just culture to a restorative justice, the initial reluctance on people to come forward with bad news is overcome, as was suggested by the literature (Dekker \& Hugh, 2010; Dekker \& Laursen, 2007).

While it would have been valuable to interview the sharp-end of the organization directly, the perspective from the managerial end is equally valuable especially in the case where the organization has recognized the gap between staff experience and the perception of it. These interviews accommodated for the staff to share their personal journey during the organizational culture change and speak openly about their experiences. Not only was this achieved, the interviewees appeared forthcoming, positive about the cultural change and motivated to continue. During the interviews, researchers were also able to identify some obstacles in the mobilization of this cultural change. These included an initial level of distrust from all staff to come forward and 
share their experiences without fear of blame. This was overcome by increased engagement of the managers with their staff, continued persistence and setting examples by doing things differently. Another obstacle was the involvement of middle-managers in the cultural change. While the researches did not investigate this further, it seemed to stem from the complicated tasks of middlemanagers that include being a bridge of coordination between both ends of the organization.

The estimates of this study are based on a relatively short window after the introduction of restorative justice, and it remains to be seen whether these savings can be sustained for a longer period. Given the unique setting, no benchmark information is available to cross-check our estimates for the economic benefit of restorative practice. Some important goals of restorative justice, however, have already been achieved, including moral engagement of stakeholders, reintegration of the caregivers into his or her community of practice, emotional healing of those affected by the incident, and, ultimately, organizational learning and improvement.

\section{REFERENCES}

Barton, C. K. B. (2003). Restorative justice: The empowerment model. Sydney, NSW: Hawkins Press.

Berlinger, N. (2005). After harm: Medical error and the ethics of forgiveness. Baltimore, MD: Johns Hopkins University Press.

Braithwaite, J. (1989). Crime, shame and reintegration. Cambridge, UK: Cambridge University Press.

Dekker, S. W. A. (2009). Just culture: Who draws the line? Cognition, Technology \& Work, 11(3), 177-185.

Dekker, S. W. A. (2016). Just Culture: Restoring trust and accountability in your organization. Boca Raton, FL: CRC Press.

Dekker, S. W. A., \& Breakey, H. (2016). 'Just culture:' Improving safety by achieving substantive, procedural and restorative justice. Safety Science, 85, 187-193.

Dekker, S. W. A., \& Hugh, T. B. (2010). Balancing "No Blame" with Accountability in Patient Safety. New England Journal of Medicine, 362(3), 275.

Dekker, S. W. A., \& Laursen, T. (2007). From punitive action to confidential reporting: A longitudinal study of organizational learning. Patient Safety \& Quality Healthcare, 5, 50-56.

Dekker, S. W. A., \& Nyce, J. M. (2013). Just culture: "Evidence", power and algorithm. Journal of Hospital Administration, 2(3), 73-78.

Hale, \& Borys. (2013). Working to rule, or working safely? Part 1: A state of the art review. Safety Science(55), 207-221.

Marx, D. (2001). Patient safety and the "just culture": a primer for health care executives. New York: Columbia University.

Mulligan, S. (2009). From retribution to repair: Juvenile justice and the history of restorative justice. University of La Verne Law Review, 31(1), 139-149.

Reason, J. T. (1997). Managing the risks of organizational accidents. Aldershot, UK: Ashgate Publishing Co.

Sharpe, V. A. (2003). Promoting patient safety: An ethical basis for policy deliberation. Hastings Center Report, 33(5), S2-19.

Sharpe, V. A. (2004). Accountability: Patient safety and policy reform. Washington, D.C.: Georgetown University Press.

von Thaden, T., Hoppes, M., Yongjuan, L., Johnson, N., \& Schriver, A. (2006). The perception of just culture across disciplines in healthcare. Paper presented at the Human Factors and Ergonomics Society 50th Annual meeting, San Francisco.

Wachter, R. M., \& Pronovost, P. J. (2009). Balancing "No Blame" with Accountability in Patient Safety. New England Journal of Medicine, 361, 1401-1406.

Weitekamp, E. (1999). The history of restorative justice. In G. Bazemore \& L. Walgrave (Eds.), Restorative Juvenile Justice: Repairing the Harm of Youth Crime, (pp. 75-102). Monsey, NY: Criminal Justice Press.

Zehr, H., \& Gohar, A. (2002). The little book of restorative justice. Intercourse, PA: Good Books. 